\title{
O PERFIL ACADÊMICO E DO CORPO DOCENTE DO CURSO DE GRADUAÇÃO EM ENGENHARIA: ESTUDO DE CASO NO CURSO DE ENGENHARIA DA COMPUTAÇÃO
}

DOI: 10.37702/2175-957X.COBENGE.2021.3489

Edson Pedro Ferlin - eferlin@live.com

CF ABENGE e UniDomBosco

Rua David Martins Lass 94

82025-190 - Curitiba - PR

Resumo: Este artigo apresenta a análise do perfil acadêmico e do corpo docente dos cursos de engenharia, em especial do curso de Engenharia da Computação, que passaram pelo processo de reconhecimento. Utiliza como parâmetros de comparação a carga horária dos componentes curriculares e o perfil do corpo docente de oito cursos de Engenharia da Computação distribuídos geograficamente em todo o Brasil. A metodologia da pesquisa utilizada é o estudo de caso dos currículos dos cursos de instituições de ensino superior, privadas e públicas, e foi utilizada a abordagem quantitativa. Os resultados auferidos destacam que as cargas horárias dos currículos analisados atendem a carga horária mínima estabelecida para os cursos de engenharia e também o perfil do corpo docente atende aos requisitos exigidos. A conclusão reitera a importância da elaboração da estrutura curricular do projeto pedagógico do curso com base nas diretrizes curriculares, de modo a atender o perfil do egresso e que o corpo docente também esteja alinhado com esse perfil profissional.

Palavras-chave: Engenharia, Currículo, Diretrizes Curriculares, Corpo Docente 


\section{O PERFIL ACADÊMICO E DO CORPO DOCENTE DO CURSO DE GRADUAÇÃO EM ENGENHARIA: ESTUDO DE CASO NO CURSO DE ENGENHARIA DA COMPUTAÇÃO}

\section{INTRODUÇÃO}

Os elementos que definem um curso de graduação são as DCNs (Diretrizes Curriculares Nacionais), no caso dos cursos de bacharelado e licenciatura, ou o Catálogo Nacional dos Cursos Superiores de Tecnologia, no caso dos cursos tecnólogos, o perfil do egresso, a estrutura curricular e os componentes curriculares (FERLIN, 2019). Todos esses elementos devem estar descritos no PPC (Projeto Pedagógico de Curso) e este deve estar alinhado com o PDI (Plano de Desenvolvimento Institucional) da Instituição de Educação Superior (IES).

Entretanto, o PPC ainda é visto, em muitos casos, como um recorte de elementos sem adequada correspondência com as ações do curso e, adicionalmente, como uma forma de cumprir as exigências legais pertinentes. Por isso, o estabelecimento de uma adequada harmonia entre os conteúdos curriculares do curso permite promover um fluxo de saberes, de habilidades e de competências que culminem não só em uma formação de um profissional apto a responder às questões técnicas, mas, também, com a visão de mundo de um cidadão comprometido com a sociedade e as suas respectivas interrelações.

A concepção do PPC deve levar em conta, também, uma visão de mundo globalizado que o egresso deve possuir e desenvolver ao longo de sua formação. Dentro dessa ótica, a globalização do profissional deve estar atrelada a um conhecimento do perfil profissional e da identidade que se deseja ter. Nesse sentido, o documento "EI Ingeniero Iberoamericano" (ASIBEI, 2007), da Associación Iberoamericana de Instituciones de Enseñanza de La Ingeniería, traça um perfil desejável para um engenheiro, mantendo as particularidades regionais e as regras de cada país, tendo como princípio a qualidade na formação do profissional.

O PPC é norteado pelas características que cada IES estabelece no modelo adotado para a sua organização acadêmica (Universidades, Centros Universitários, Institutos Federais de Tecnologia, Faculdades) e para a sua organização administrativa (Federal, Estadual, Comunitárias, Confessionais e Particulares). No livro "A Universidade no Brasil: concepções e modelos" (MOROSINI, 2006) é apresentado, de maneira objetiva, o sistema educacional superior do Brasil, o que permite entender a missão e a atuação das IES, conforme o modelo adotado.

Nesse sentido, a estrutura curricular de um curso de graduação é composta pelos diversos Componentes Curriculares, como disciplinas (Obrigatórias, Optativas e Eletivas), Projetos Integradores, Atividades Complementares, Trabalho de Conclusão de Curso (TCC), Estágio Curricular e outros.

O problema de pesquisa pode ser caracterizado pela necessidade contínua de melhoria da qualidade do ensino no Brasil (GODINHO et al., 2015) a partir do estudo dos currículos e do corpo docente de cursos de engenharia. Na tentativa de colaborar com a solução deste problema este artigo tem por objetivo analisar o currículo e o corpo docente de oito cursos de engenharia, em especial de cursos de Engenharia da Computação, que passaram pelo processo de reconhecimento no período de 2018 e 2019.

Justifica-se tal esforço pela necessidade de entender o perfil acadêmico e do corpo docente e que influenciam a formação dos engenheiros, visando fornecer subsídios para 
a estruturação dos currículos dos cursos de engenharia, e que estejam em sintonia com o mercado de trabalho (FERLIN \& TOZZI, 2008). Fato que por si só justifica a relevância do estudo frente às necessidades de melhoria na formação e qualidade dos engenheiros no Brasil para atenderem às demandas impostas por esse mundo globalizado e tecnológico.

\section{FUNDAMENTAÇÃO LEGAL}

Um currículo de um curso de graduação deve levar em conta alguns elementos fundamentais sob o aspecto legal que são a DCN, definição da carga horária mínima e o tempo de integralização do curso.

\subsection{Diretrizes Curriculares}

As DCNs são um conjunto de definições doutrinárias sobre princípios, fundamentos e procedimentos na educação que orientam as IES na organização, articulação, desenvolvimento e avaliação de suas propostas pedagógicas. As DCNs têm origem na Lei de Diretrizes e Bases da Educação (LDB), de 1996, que assinala ser incumbência da União "estabelecer, em colaboração com os estados, Distrito Federal e os municípios, competências e diretrizes para a Educação, que nortearão os currículos e os seus conteúdos mínimos, de modo a assegurar a formação básica comum".

O curso de Engenharia de Computação segue o disposto na Resolução CNE/CES no 11 de 11 de março de 2002 (MEC, 2002), que institui DCN dos Cursos de Graduação em Engenharia, e a Resolução CNE/CES no 5, de 16 de novembro de 2016 (MEC, 2016) que institui a DCN para os cursos de graduação na área da Computação, dentre eles o curso de Engenharia de Computação, o que muitas vezes gera uma dubiedade.

Contudo, é importante ressaltar que desde 2019 há uma nova DCN para as Engenharias, Resolução CNE/CES n 1 de 23 de janeiro de 2019 (MEC, 2019), e os cursos de engenharia deverão se adequar a essa nova resolução.

\subsection{Carga Horária}

A carga horária mínima de um curso de graduação está estabelecida na Resolução CNE/CES no 2 de 18 de junho de 2007 (MEC, 2007a), e em específico para os cursos de engenharia foi estabelecida a carga horária de 3600 horas.

A Resolução CNE/CES n 3 de 2 de julho de 2007 (MEC, 2007b) estabelece que a mensuração das carga horárias deve ser em horas e não horas-aula. Entretanto, muitas IES utilizam a mensuração dos componentes curriculares em termos de hora-aula, e por isso é obrigatório explicitar no PPC a duração da hora-aula e como é realizada contabilização em horas-relógio.

\subsection{Duração do Curso}

A duração dos cursos de graduação, em particular dos cursos de engenharia, também está definido na Resolução CNE/CES no 2 de 18 de junho de 2007 (MEC, 2007a). Nessa resolução está expresso que para os cursos de engenharia o tempo mínimo de integralização é de 5 anos, mas pode ter uma duração diferenciada desde que devidamente justificada no PPC. 


\section{METODOLOGIA DA PESQUISA}

Neste estudo adotou-se o Estudo de Caso como método de pesquisa para poder analisar a estrutura curricular e o corpo docente de cursos de Engenharia da Computação e na pesquisa foi adotado a técnica de pesquisa Quantitativa para mensurar os dados coletados (GERHARDT \& SILVEIRA, 2009; GIL, 2007; YIN, 2015).

A pesquisa foi composta por duas fases: a coleta de dados, que envolve o levantamento dos dados sobre o tema, utilizando para isso o método de pesquisa Estudo de Caso, considerando oito cursos de Engenharia da Computação, na modalidade Presencial, de IES distribuídas geograficamente pelas 5 regiões (Sul, Sudeste, CentroOeste, Norte e Nordeste) do Brasil; e a Análise Estatística dos dados obtidos segundo as práticas recentes apresentadas por Fávero e Belfiore (2017). Para a delimitação deste caso, e universo de pesquisa, foram considerados os cursos de Engenharia da Computação que passaram pelo processo de reconhecimento do MEC em 2018 e 2019.

O corte deste universo foi realizado em torno das informações sobre estrutura curricular e corpo docente dos cursos de Engenharia da Computação. Antes que os dados fossem enviados para os pesquisadores eles passaram por um processo de anonimização para garantir os direitos de privacidade dos cursos/IES sem alterar a significância dos dados. Estes dados foram obtidos na internet/documentos e só então distribuídos à equipe de pesquisa. A manipulação destes dados foi realizada em planilha eletrônica de forma permitir a análise estatística (SILVESTRE, 2007). Esta análise foi realizada com as ferramentas matemáticas disponíveis no software Excel da Microsoft.

Os cursos de Engenharia da Computação analisados são de IES que possuem as seguintes características: a) IES\#1: Faculdade particular (região Sul); b) IES\#2: Universidade pública (região Centro-Oeste); c) IES\#3: Universidade comunitária (região Sul); d) IES\#4: Faculdade particular (região Sudeste); e) IES\#5: Universidade particular (região Centro-Oeste); f) IES\#6: Faculdade particular (região Norte); g) IES\#7: Instituto Federal (região Sudeste); g) IES\#8: Instituto Federal (região Nordeste).

\section{ANÁLISES E RESULTADOS}

As análises foram divididas em dois estudos: a) Perfil Acadêmico, em que se analisaram os aspectos relacionados à estrutura curricular dos cursos de Engenharia da Computação; b) Perfil do Corpo Docente, no qual foram analisados os aspectos relacionados à titulação, tempo de dedicação e produção técnico-científica dos professores que atuam nesses cursos.

Os estudos foram realizados considerando-se a organização acadêmica (Universidades, Centros Universitários, Institutos Federais de Tecnologia, Faculdades) e também a organização administrativa (Federal, Estadual, Comunitárias, Confessionais e Particulares).

Contudo, ressalta-se que na pesquisa não se conseguiu contemplar os cursos de IES categorizados com a Organização Acadêmica (Centros Universitários) e na Organização Administrativa (Estaduais e Confessionais). 


\section{PERFIL ACADÊMICO}

Os currículos dos cursos selecionados estão em consonância com a DCN das Engenharias de 2002 que estabeleceu a carga horária mínima de 3600 horas, e também à nova DCN para as Engenharias aprovada pelo Parecer CNE/CES n ${ }^{\circ} 1$ de 23 de Janeiro de 2019 e homologada em 23 de abril de 2019 (MEC, 2019).

Destaca-se ainda que nesse estudo as cargas horárias são expressas em horas conforme estipulado pelo Conselho Nacional de Educação (CNE) na Resolução CNE/CES $n^{\circ} 3$ de 2 de julho de 2007 (MEC, 2007b).

\subsection{Carga Horária Total}

Observando o Gráfico 1 percebe-se que a carga horária total dos cursos analisados estão com carga horária igual ou superior à carga horária mínima estabelecida para os cursos de engenharia, que é de 3600 horas.

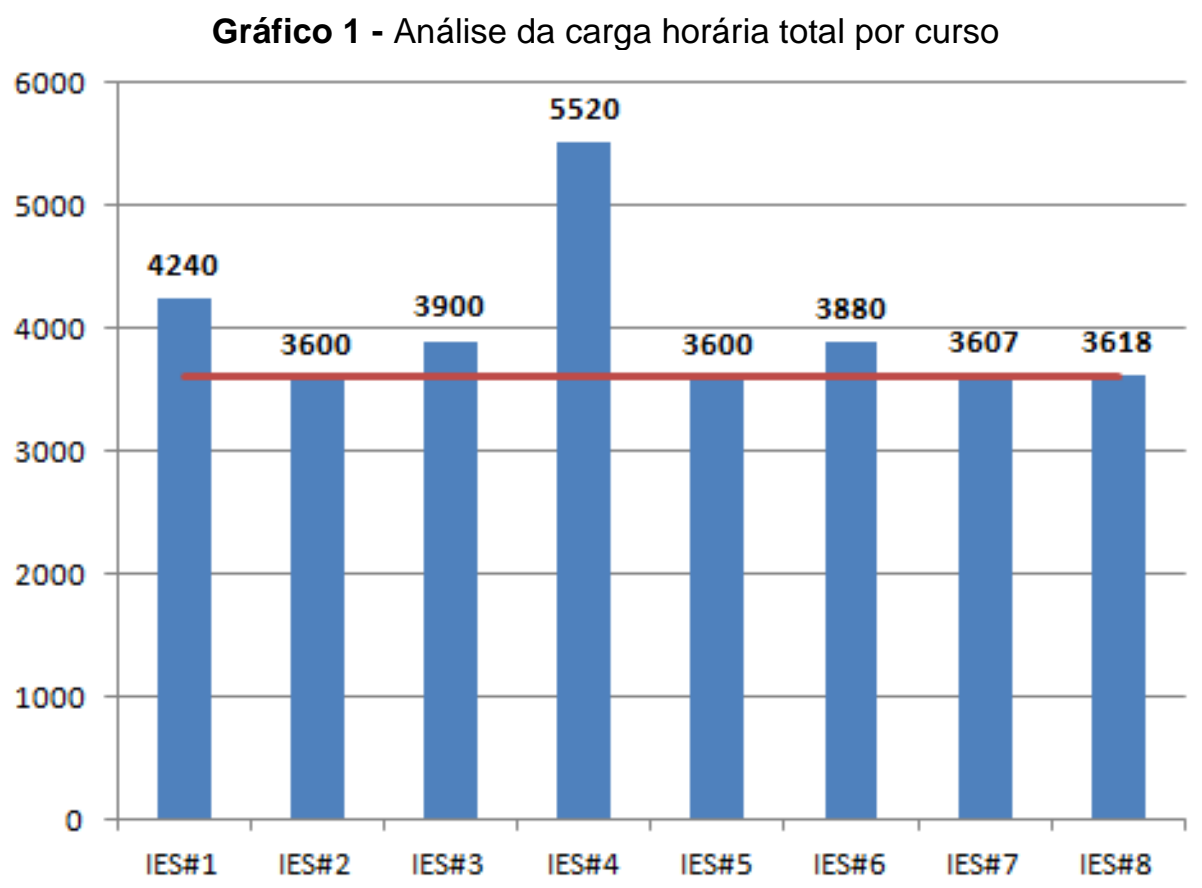

Fonte: os autores (2021)

Contudo, há de se fazer um destaque para o curso IES\#4 que possui uma carga horária bem acima do estabelecido e isto é em decorrência de uma abordagem voltada ao estudo de tempo integral.

Quando se realiza o comparativo considerando a Organização Administrativa, como apresentado no Gráfico 2, percebe-se que a carga horária total dos cursos das IES públicas é praticamente o mínimo estabelecido de 3600 horas, e os maiores valores são contabilizados nos cursos de IES particulares. 
Gráfico 2 - Análise da carga horária total por organização administrativa

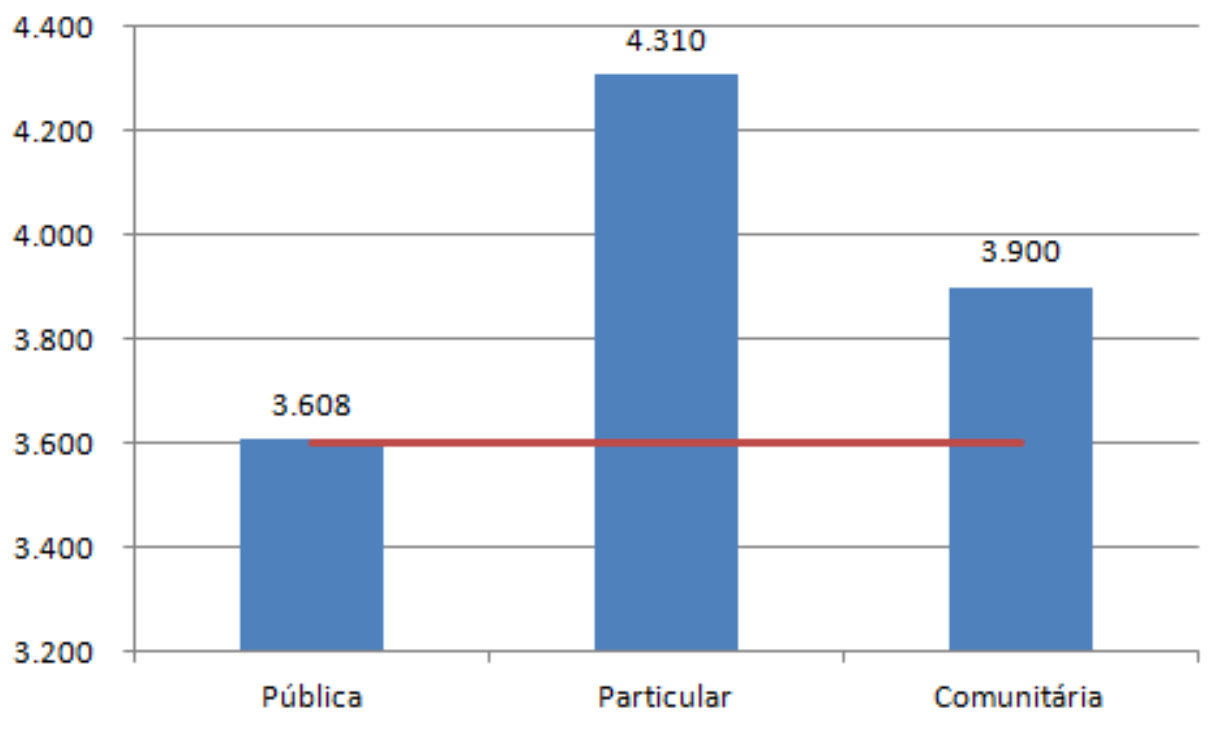

Fonte: os autores (2021)

\subsection{Carga Horária em Disciplinas}

Se for comparada somente a carga horária em disciplinas, percebe-se que a carga horária está em torno de 3300 horas, apresentando um valor destoante no curso IES\#4, como mostrado no Gráfico 3, em que vale o mesmo apontamento realizado no item 4.1.

Gráfico 3 - Análise da carga horária das disciplinas por curso

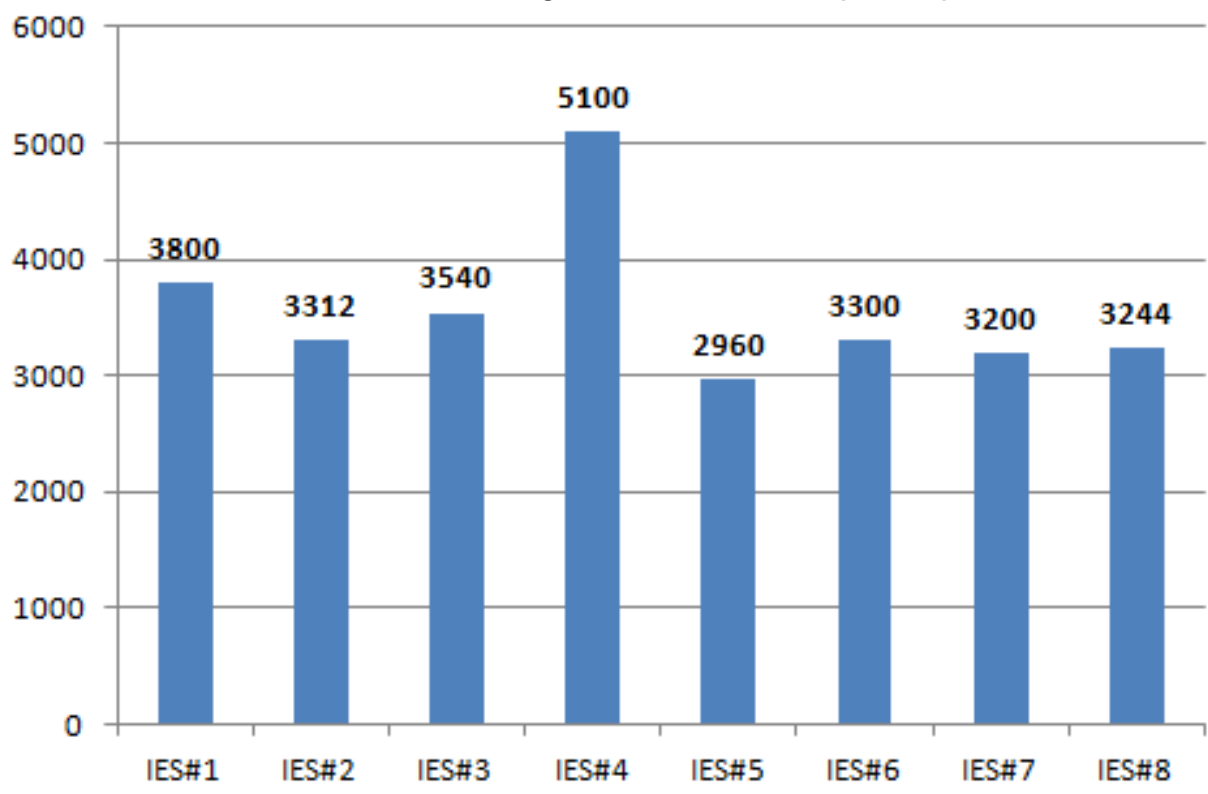

Fonte: os autores (2021)

\subsection{Carga Horária em Conteúdos Complementares}

No Gráfico 4 tem-se a carga horária destinada aos Conteúdos Complementares (TCC, Estágio Supervisionado, Atividades Complementares e outros). Constata-se que a partir da implantação da DCN de Engenharia em 2002, que estabeleceu a obrigatoriedade do TCC e do Estágio Supervisionado, e também a recomendação da adoção das 
Atividades Complementares, os cursos de engenharia passaram a incorporar uma maior carga horária destinada aos conteúdos complementares, em especial às Atividades Complementares, com um valor médio de 439 horas.

Gráfico 4 - Análise da carga horária dos conteúdos complementares por curso

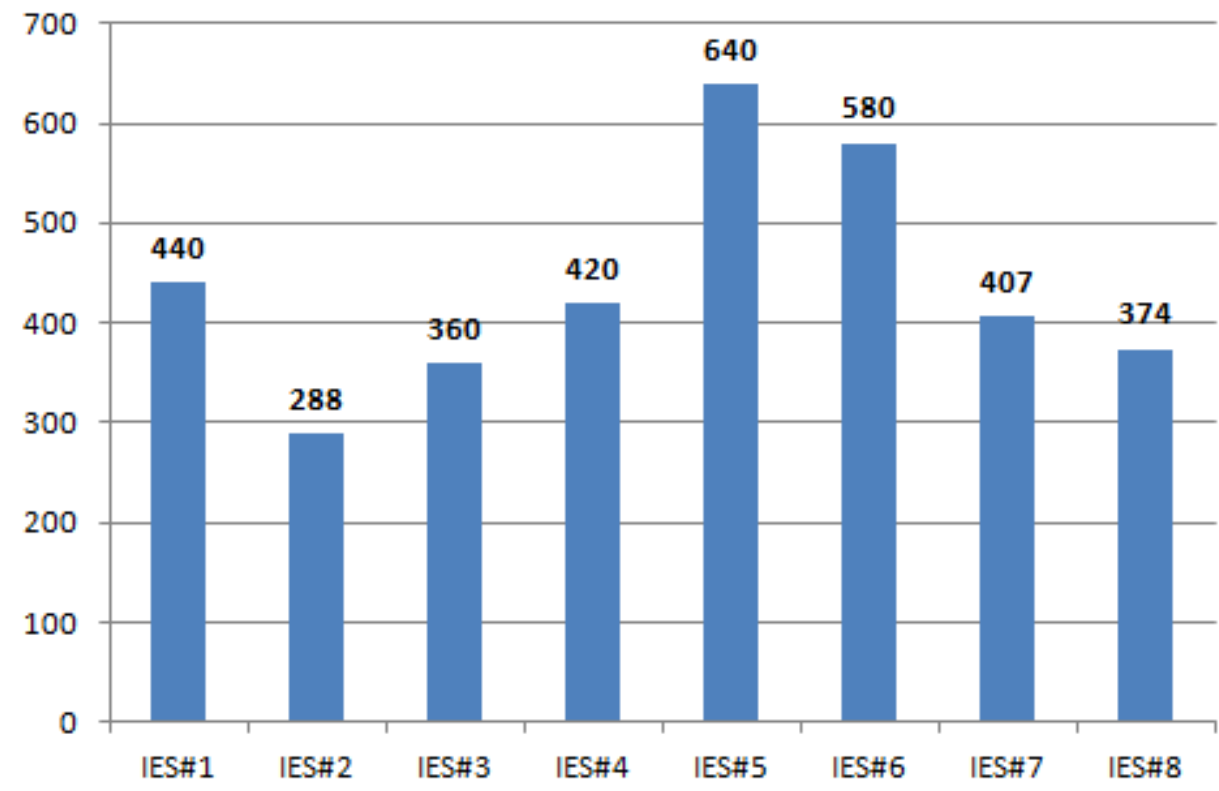

Fonte: os autores (2021)

No detalhamento dos Conteúdos Complementares, percebe-se que houve uma maior diversidade de conteúdos, como mostrado no Gráfico 5, o que favorece uma maior adequação da formação ao mercado de trabalho, com o TCC, Estágio Supervisionado e as Atividades Complementares.

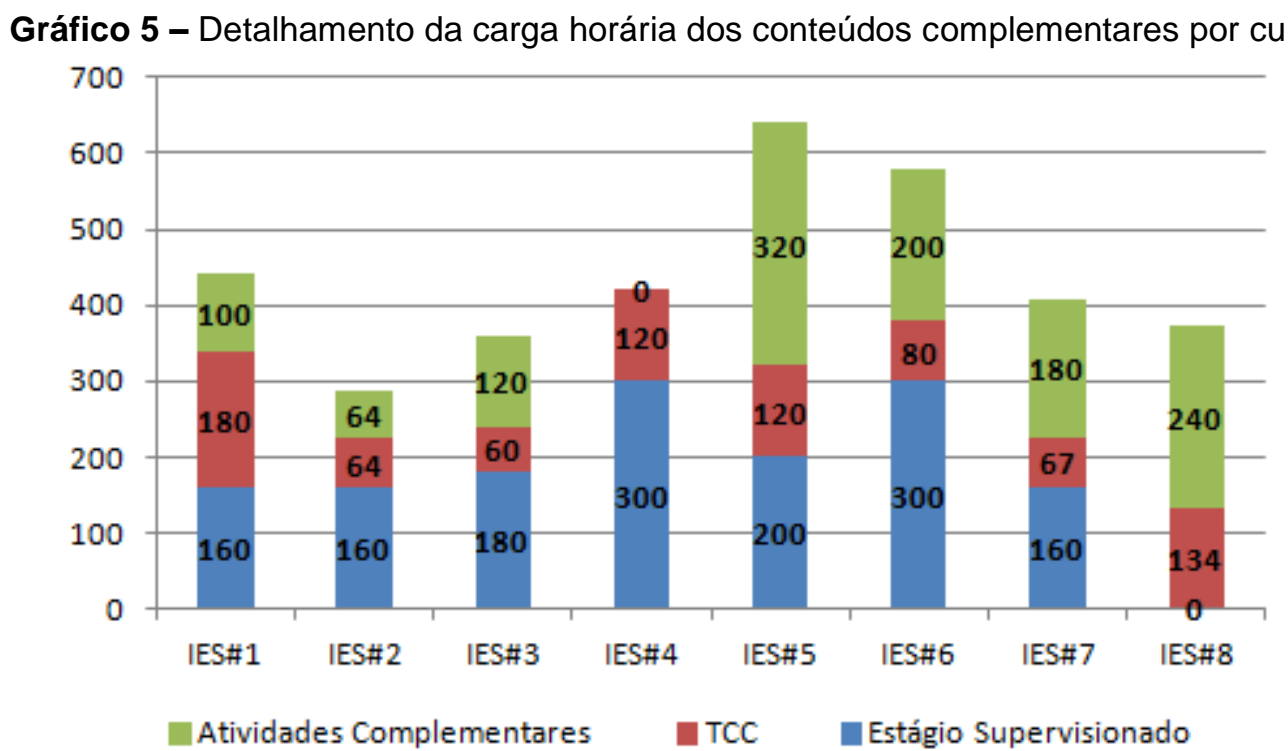

Fonte: os autores (2021)

Destaca-se que o curso IES\#4 não contempla outros conteúdos complementares exceto o TCC e o Estágio Supervisionado.

Salienta-se também que o curso IES\#8 não adota o Estágio Supervisionado, pois segue o disposto na DCN para cursos na área de Computação, Resolução CNE/CES nº 
5, de 16 de novembro de 2016 (MEC, 2016), que não exige a sua obrigatoriedade, ficando a decisão a cargo do curso.

\section{PERFIL DO CORPO DOCENTE}

Com base nos dados coletados dos oito cursos de Engenharia da Computação, foi possível também traçar um perfil do corpo docente desses cursos, considerando a titulação acadêmica, regime de trabalho e produção técnico-científica.

\subsection{Titulação Acadêmica}

Observando o Gráfico 6 percebe-se que a maior porcentagem de professores com a titulação de Doutor está nas IES públicas $(54,1 \%)$, enquanto que a menor porcentagem está nos cursos das IES particulares (32,0\%). Destaca-se também que a porcentagem de Mestres é praticamente a mesma nos cursos das três tipos de Organização Administrativa. Ainda, percebe-se que os cursos de IES particulares é que apresentam uma maior porcentagem média de professores com Especialização (18\%).

Gráfico 6 - Análise da titulação acadêmica do corpo docente por organização administrativa

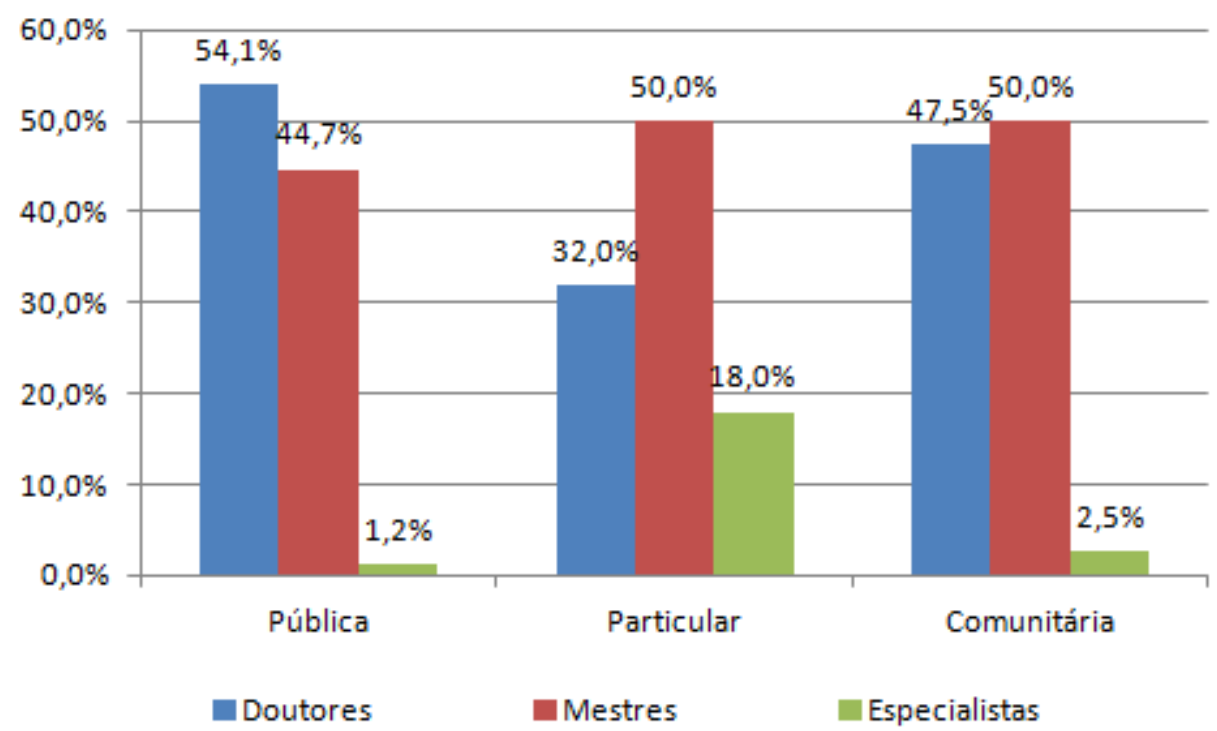

Fonte: os autores (2021)

Quando se analisa a distribuição da titulação acadêmica dos professores dos cursos analisados nas regiões (Sul, Sudeste, Centro-Oeste, Norte e Nordeste), como mostrado no Gráfico 7, percebe-se que a região Sul apresenta a maior porcentagem de professores com mestrado $(58,3 \%)$. Por sua vez, na região Nordeste há uma maior porcentagem de professores com doutorado (61,9\%). Destaca-se ainda, que a região Norte é que apresenta a maior porcentagem de professores com especialização $(21,4 \%)$. Contudo, ressalta-se que os valores decorrentes das regiões Norte e Nordeste são preliminares, pois foram analisados somente um curso em cada uma dessas regiões. 
Gráfico 7 - Análise da titulação acadêmica do corpo docente por região geográfica no Brasil

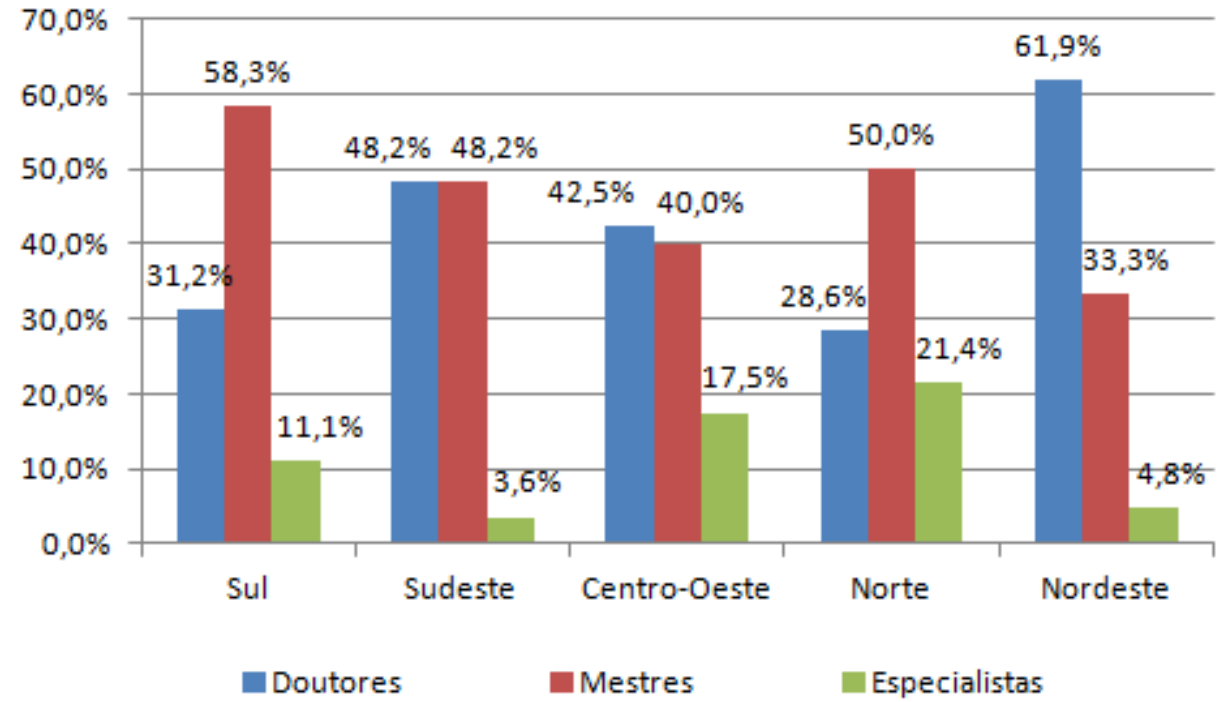

Fonte: os autores (2021)

\section{5 Índice de Qualificação do Corpo Docente (IQCD)}

Outro comparativo que se pode realizar é analisar o IQCD dos cursos estudados. O Índice de Qualificação do Corpo Docente (IQCD), conforme Nota Técnica n 16/2017 e Revisão Nota Técnica oㅡ 2/2018/CGACGIES/DAES, é utilizado pelo Tribunal de Contas da União (TCU), para que as instituições e cursos possam ser mais bem contextualizados. Esse índice é calculado pela Equação (1), onde D, M, E e G, correspondem respectivamente à quantidade de Doutores, Mestres, Especialistas e Graduados atuando no curso.

$$
I Q C D=\frac{(5 * D)+(3 * M)+(2 * E)+G}{(D+M+E+G)}
$$

Observando-se o Gráfico 8 , os menores valores $(2,77$ e 3,11$)$ correspondem a cursos que possuem as menores porcentagem de Doutores e também as maiores porcentagens de professores Especialistas. Por outro lado, os cursos que apresentam as maiores porcentagens de professores Doutores e também as mais baixas porcentagens de Especialistas apresentam os maiores valores de IQCD. 
Gráfico 8 - Análise do IQCD por curso

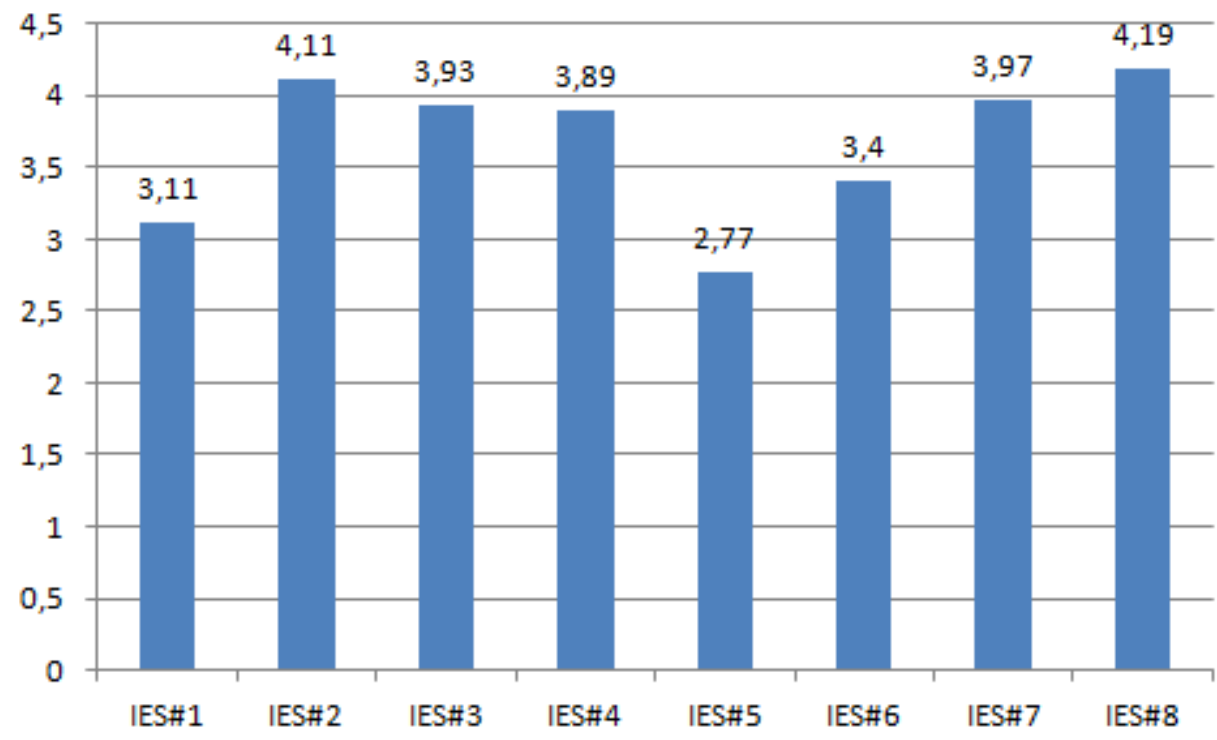

Fonte: os autores (2021)

\subsection{Tempo de Dedicação}

Observando o Gráfico 9 percebe-se que nos cursos das IES públicas a totalidade dos professores possui a dedicação de Tempo Integral (TI). Por outro lado, nos cursos das IES particulares e comunitárias o percentual médio de $\mathrm{TI}$ é de $30,0 \%$, e de professores Tempo Parcial (TP) é de 41,8\%. Contudo, destaca-se que nos cursos das IES particulares há uma predominância de professores Horistas (44,0\%).

Gráfico 9 - Análise do tempo de dedicação por organização administrativa

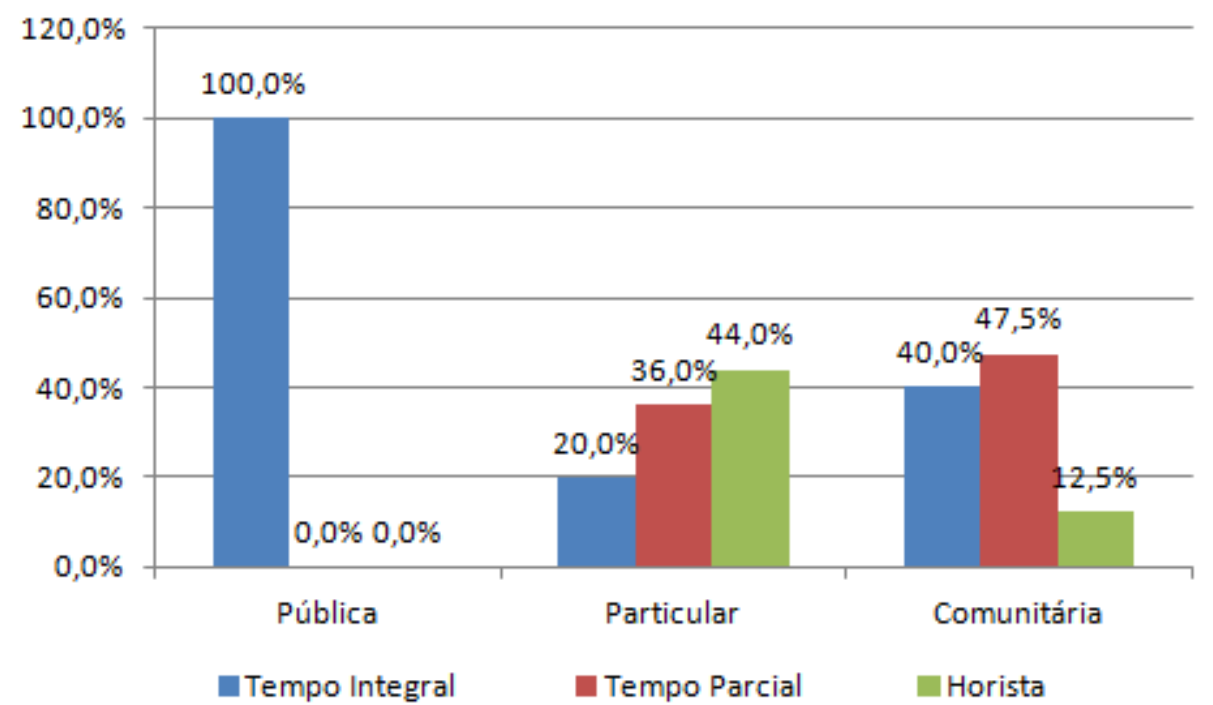

Fonte: os autores (2021)

\subsection{Produção Técnico-Científica}

Se for analisada a produção técnico-científica estratificada por Organização Acadêmica, considerando os últimos três anos, segundo critério do MEC, percebe-se que os cursos dos Institutos Federais detêm o menor percentual de professores que não possuem produção técnico-científica $(25,0 \%)$ no triênio, enquanto que os cursos das 
Faculdades detêm o maior percentual (43,0\%) de professores que não possuem qualquer produção nesse período, como pode ser observado o Gráfico 10.

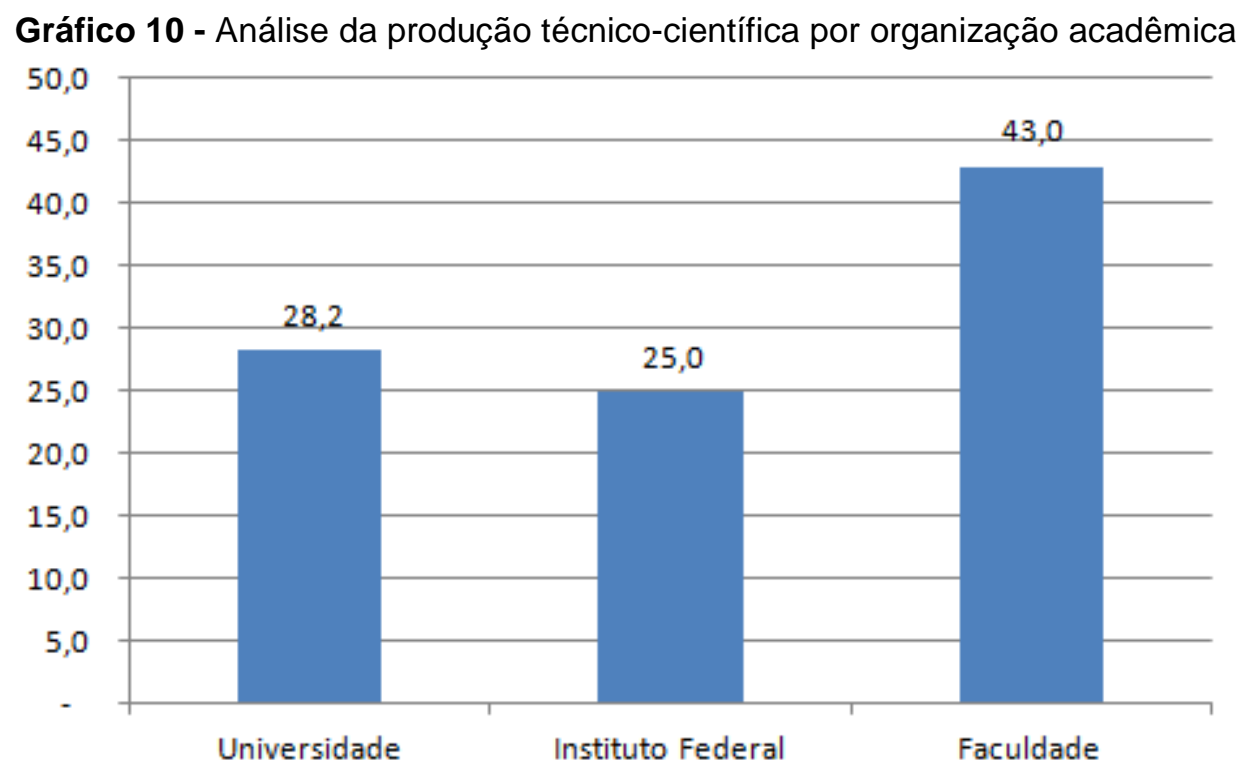

Fonte: os autores (2021)

\section{CONSIDERAÇÕES FINAIS}

Nesse estudo foi realizada a análise do perfil acadêmico e do corpo docente de oito cursos de Engenharia da Computação, que passaram pelo processo de reconhecimento nos anos 2018 e 2019, e que estão distribuídos geograficamente nas cinco regiões (Sul, Sudeste, Centro-Oeste, Norte e Nordeste) do Brasil.

O objetivo do trabalho foi alcançado, uma vez que foi possível traçar tanto o perfil acadêmico quanto do corpo docente do curso de Engenharia da Computação, considerando os cursos/IES espalhados por todas as regiões do Brasil que ofertam o curso na modalidade presencial.

Em termos do Perfil Acadêmico, de maneira geral, consta-se que a carga horária total dos cursos analisados é superior à mínima estipulada, de 3600 horas, sendo que a carga horária em disciplinas está em torno de 3300 horas. O que se percebe é que os currículos a partir da DCN 2002 passaram a ter uma maior carga horária e diversidade de Conteúdos Complementares (TCC, Estágio Supervisionado, Atividades Complementares e outros), e esse fato favorece a uma melhor adequação ao mercado de trabalho.

O estudo do Perfil do Corpo Docente apontou o seguinte panorama: a) em termos de titulação, nos cursos das IES públicas há um maior percentual de Doutores, enquanto nos cursos das IES particulares há um percentual maior de Especialistas; b) no quesito tempo de dedicação, nos cursos das IES públicas a totalidade dos professores tem regime $\mathrm{TI}$, enquanto que nos cursos das IES particulares há uma predominância de professores horistas; e por último, c) a análise de produção técnico-científica, indicou que há um descompasso, pois pelo menos $25,0 \%$ podendo chega a $43,0 \%$ dos professores Não apresenta qualquer produção técnico-científica nos últimos três anos, o que é um fator preocupante.

Por fim, esse estudo não tem a pretensão de encerrar o assunto e acaba por induzir novos problemas de pesquisa relacionados aos motivos que levam a falta de produção técnico-científica dos professores, a questão da distribuição por titulação nas 
diversas regiões, e ainda a expansão desse universo para outros cursos/IES têm o potencial de permitir uma caracterização mais precisa dos perfis Acadêmico e do Corpo Docente.

\section{REFERÊNCIAS}

ASIBEI. El ingerino iberoamericano. Bogotá-Colômbia: ASIBEI, 2007.

FÁVERO, L.P.; BELFIORE, P. Manual de análise de dados: estatística e modelagem multivariada com excel, SPSS e Stata. Editora Elsevier, 2017.

FERLIN, E.P. Análise do currículo de cursos de engenharia nos últimos 20 anos (1998 2018): estudo de caso nos cursos de engenharia da computação. In: COBENGE 2019 XLVII Congresso Brasileiro de Ensino de Engenharia e II Simpósio Internacional de Educação em Engenharia da Abenge. Anais. Fortaleza-CE: Abenge, 2019.

FERLIN, E.P.; TOZZI, M.J. Análise sobre o mercado de trabalho para o engenheiro no Brasil: uma visão geral. Mais e Melhores Engenheiros. Brasília-DF: Abenge, 2008.

GERHARDT, T.E.; SILVEIRA, D.T. (Org.). Métodos de pesquisa. Série Educação a Distância 1. ed. Porto Alegre-RS: Editora da UFRGS, 2009.

GODINHO, N.B.; GONCALVES, R.B.; DE ALMEIDA, A.S., 2015. Digital and information literacy in higher education: a study with students in Universidade Federal do Rio Grande-FURG/Competências digitais e informacionais no ensino superior: um estudo com acadêmicos na Universidade Federal do Rio Grande--FURG. Revista Digital de Biblioteconomica e Ciência da Informação, 13(2), pp.437-455.

GIL, A.C. Como elaborar projetos de pesquisa. 4. ed. São Paulo-SP: Atlas, 2007.

MEC. Diretriz para cursos de engenharia - RESOLUÇÃO CNE/CES n 11 de 11 de março de 2002. MEC. Disponível em: http://portal.mec.gov.br/cne/arquivos/pdf/CES112002.pdf. Acesso em: abril 2021, 2002.

MEC. Carga horária mínima - RESOLUÇÃO CNE/CES nº 2 de 18 de junho de 2007. MEC. Disponível em: http://portal.mec.gov.br/cne/arquivos/pdf/2007/rces002_07.pdf. Acesso em: abril 2021, 2007.

MEC. Conceito de hora-aula - RESOLUÇÃO CNE/CES n ${ }^{\circ} 3$ de 2 de julho de 2007. MEC. Disponível em: http://portal.mec.gov.br/cne/arquivos/pdf/2007/rces003_07.pdf. Acesso em: abril 2021, 2007.

MEC. Diretriz para cursos na área de computação - RESOLUÇÃO CNE/CES $n^{\circ} 5$ de 16 de novembro de 2016. MEC. Disponível em: http://portal.mec.gov.br/index.php?option=com_docman\&view=download\&alias=52101rces005-16-pdf\&category_slug=novembro-2016-pdf\&Itemid=30192. Acesso em: Abril 2021, 2016.

MEC. Diretriz para cursos de engenharia - RESOLUÇÃO CNE/CES $n^{0} 1$ de 23 de janeiro de 2019. MEC. Disponível em: http://portal.mec.gov.br/docman/janeiro-2019pdf/106051-pces821-18/file. Acesso em: Abril 2021, 2019. 
MOROSINI, M. C. (Org). A Universidade no Brasil: concepções e modelos. BrasíliaDF: INEP, 2006.

SILVESTRE, A.L. Análise de dados e estatística descritiva. São Paulo-SP: Escolar editora, 2007.

YIN, R.K. Estudo de caso: planejamento e métodos. 5. ed. Porto Alegre-RS: Bookman, 2015.

\title{
THE ACADEMIC AND FACULTY PROFILE OF ENGINEERING PROGRAM: CASE STUDY OF THE COMPUTER ENGINEERING PROGRAM
}

\begin{abstract}
This paper presents the analysis of the academic and faculty profile of engineering programs, in particular in the Computer Engineering program, which went through the recognition process. It uses as parameters of comparison the workload of the curricular content and the faculty profile of eight Computer Engineering programs distributed geographically in Brazil. The research methodology used is the case study of the program curriculums of higher education institutions, private and public and the quantitative approach was used. The results earned hourly highlight that the workloads of the analyzed curricula meet the minimum workload established for engineering programs and also the faculty profile meets the required requirements. The conclusion reiterates the importance of the development of the curricular structure of the pedagogical project of the course based on the curricular guidelines, to meet the profile of the graduate and that the faculty is also aligned with this professional profile.
\end{abstract}

Keywords: Engineering, Curriculum. Curriculum Guidelines, Faculty. 